\title{
An economic valuation of access to cultural institutions: museums, theatres, and cinemas
}

\section{Aleksandra Wiśniewska ${ }^{1}$ (D) Wiktor Budziński ${ }^{1} \cdot$ Mikołaj Czajkowski $^{1,2}$}

Received: 21 January 2019 / Accepted: 7 January 2020 / Published online: 18 February 2020

(c) The Author(s) 2020

\begin{abstract}
Cultural institutions are the main beneficiaries of public funds for culture. However, cultural policies suffer from 'adhocism' in the administration of institutions, which are often publicly owned and receive little recognition of the benefits that society gains from their use. The aim of this study is to provide the measurement of the use value of access to cultural institutions. Based on the observed individual attendances and their costs, a two-stage budgeting model is employed to estimate the change in consumer surplus related to the loss of access to cinemas, museums, and theatres in Warsaw, Poland. It is the first non-market valuation of cinemas in the existing literature. The inclusion of institutions' entire markets helps to overcome the bias caused by the embedding effect and the availability of substitutes, which affects many single-site valuations. The estimated use values are compared with the subsidies received by the three groups of cultural institutions. Results reveal substantial benefits provided by cinemas, although cinemas are nearly excluded from the circulation of public support. The estimated use value is enough to justify subsidies for both highly subsidised sectors of museums and theatres. The estimation of use values serves as a starting point for the evaluation of the use of public resources.
\end{abstract}

Keywords Cultural policy $\cdot$ Funding the arts $\cdot$ Theatre $\cdot$ Museum $\cdot$ Cinema $\cdot$ Nonmarket valuation

JEL Classification $\mathrm{Z} 1 \cdot \mathrm{Z} 11 \cdot \mathrm{Z} 18 \cdot \mathrm{D} 61$

Electronic supplementary material The online version of this article (https://doi.org/10.1007/s 1082 4-020-09375-3) contains supplementary material, which is available to authorized users.

Aleksandra Wiśniewska

awisniewska@wne.uw.edu.pl

Mikołaj Czajkowski

mc@uw.edu.pl

1 Faculty of Economic Sciences, University of Warsaw, Warsaw, Poland

2 Environment Centre, Charles University, Prague, Czech Republic 


\section{Introduction}

Cultural institutions are the main beneficiaries of public support for culture in many countries, especially in Europe. They are also responsible for the provision of cultural accessibility for society as a whole, which is one of the main goals for cultural policies (Hausner et al. 2013). Cost-benefit analysis has become a standard evaluation methodology used in policy-making in OECD countries (OECD 2006), including the USA (US Office of Management and Budget 1992) and the UK, the leader for evidence-based cultural policies in Europe (O'Brien 2010; HM Treasury 2018)

Knowledge about people's preferences helps to decide where to invest resources to achieve the best value. According to the rule of consumer sovereignty, the costs of governmental expenditures are justifiable if they do not exceed the benefits gained as a result of these expenditures. Access to cultural institutions is often free, and entrance prices are not necessarily related to the true costs of producing and providing cultural goods (Bakhshi et al. 2015). Nonetheless, economic valuation techniques can still be used-based on the visitation behaviour of consumers, for example, with respect to travel costs-to estimate the demand function and the resulting consumer surplus (CS) (i.e. economic benefits in terms of welfare gains) (Hanley and Czajkowski 2017).

The aim of the article is to study preferences for the access to a range of recognisable institutions within three cultural markets: museums, theatres, and cinemas in Warsaw, the capital city of Poland. We use a two-stage budgeting model that combines a site choice model with a count data model, while employing travel cost data. As a result, we are able to estimate the benefits associated with access to cultural venues, as well as cultural markets as a whole. We employ the estimated use values as a starting point for the evaluation of the division of public resources within cultural branches. Critically, using revealed preferences we limit the estimation of benefits to the scope of use values, not estimating other components of economic value of the institutions (e.g. passive use value). We also do not discuss other, non-economic sources of its value, cultural value as the most important (Angelini and Castellani 2018).

In Poland, governments are legally obliged to support publicly owned cultural institutions. Specifically in Warsaw, the city with the biggest and most complex cultural market in the country, cultural institutions received an average of $82 \%$ of the local public cultural budget from 2008-2014, reaching 87\% in 2014 (Hausner et al. 2015, p. 59). However, there is little recognition of whether they receive comparable support from wider society. This type of cultural policy is the result of historical dependencies rather than conscious decisions of policy-makers (Hausner et al. 2015; Lewandowska 2018; Murzyn-Kupisz 2010; Wassowska-Pawlik 2013). Moreover, the institutionalisation of the policy by the city also means there exists insufficient space for including non-public actors. Recent studies show that people do not pay attention to whether the cultural offer is provided by the public or the private sector (Behr et al. 2016), and publicly organising cultural institutions does not automatically result in the highest levels of 
effectiveness in the provision of accessibility, visitor's experience, and relation to the local context (Bertacchini et al. 2018).

Changes to the customs and traditions of the division of public resources have encountered historical, political, and legal constraints in many countries. Continental Europe suffers from 'adhocism' in the administration of institutions (Van Den Hoogen 2014; Ulldemolins and Arostegui 2013). The domination of public ownership of cultural institutions and public support within the budgets of cultural venues is not just the case for Poland; however, the European field provides diverse solutions for the financing culture. For instance, legal state ownership is predominant in German and Austrian theatres too (Zieba 2011). Poland's neighbouring countries share its communistic heritage in the form of public supervision for cultural institutions, raising anxiety about the possibility of unjustified interventions from politicians into their cultural management (Vojtíšková and Lorencová 2015). Considering that public ownership is not sufficient to justify public engagement (Galloway and Dunlop 2007), we provide the starting point for the evaluation of the local cultural policies carried out predominantly by the strength of public cultural institutions.

Our study contributes to the field of cultural economics and cultural policy research in a few ways. First, to the best of our knowledge, we provide the first nonmarket valuation of access to cinemas. Therefore, we extend the use of revealed preferences within cultural economics. It is also the first use of a two-stage budgeting model, as is typical for valuations of recreational sites, within the field of cultural economics. Significantly, the subject of the vast majority of non-market valuation studies of cultural goods and services is limited to a particular good or institution; for a review of this research, see Noonan (2002, 2003). However, eliciting preferences for a single good raises concerns regarding the reliability of the results, as they can be affected by the so-called embedding effect (consumers may associate other goods with the studied good) and the availability of substitutes (the loss of a good could be less meaningful if people have the option to switch to similar goods). We lessen the impact of these problems by including the entire cultural markets of cultural institutions (theatres, cinemas, and museums) in this study. Finally, by examining a broad group of cultural institutions, we give rise to an open-minded evaluation of cultural policies that would transcend the historical dependencies and long-lasting traditions of culture financing.

This paper is organised as follows. The case study is described in the next subsection. Section 2 presents an in-depth literature review of the non-market valuation of cultural institutions, with an emphasis on the application of revealed preference-based methods and embedding effect challenges. The data and case study used for the empirical research are described in Sect. 3. Section 4 contains a presentation of the methods employed. In Sect. 5, we present the results of the two stages of econometric procedures that lead to the estimation of the benefits related to the access of cultural institutions and the associated cost-benefit relationship, which drive certain policy implications that are discussed in Sect. 6. The last section summarises and offers conclusions. 


\section{Literature review on the economic value of culture}

Non-market valuation techniques have been developed since the $1960 \mathrm{~s}$ to address problems with estimating the benefits gained by consumers of public and mixed goods. As culture has the necessary features of public goods (Throsby and Ginsburgh 2006, p. 7; Throsby 2001) that make it difficult to value using market transactions, non-market valuation tools allow us to properly estimate the benefits that people gain from them.

Researchers in economics have two main sources of data for the analysis of consumer preferences: revealed and stated preferences. The former refers to choices observed in real market situations. Conversely, stated preference data refer to hypothetical choices, although they are typically made under incentive compatible conditions (Carson 2012). Despite ongoing research aiming to deal with the problem of hypothetical market bias (e.g. Carson and Groves 2007; Czajkowski et al. 2017; Zawojska and Czajkowski 2017, Zawojska and Bartczak 2019) and embedding (Hausman 2012, Kling et al. 2012), stated preference methods remain relatively controversial. For this reason, whenever appropriate data are available, revealed preference methods are preferred. Even though revealed preferences capture only use values (ignoring the fact that people may support and be willing to pay for things they do not actually use) and can rarely be used to evaluate the effects of future changes, they provide a useful and relatively uncontroversial tool for valuation and policymaking (Pearce et al. 2006). ${ }^{1}$ The review of the literature below focuses on revealed preference-based valuations of the three kinds of cultural institutions (museums, theatres, and cinemas).

People travel to visit cultural sites in their free time. Turning up at a site demonstrates positive net value from the visit for a visitor. Because numerous cultural venues charge little-to-no entry fees, it is impossible to trace out a demand curve (and, consequently, measure the CS as an expression of the use value) for visits on the basis of ticket prices. However, this can be performed with the varying costs of travel (Navrud and Ready 2002). Travel cost data are the most common source of value in revealed preference-based research.

There are two types of travel cost models used in the literature. The first, visitation frequency models, analyses the number of visits to a given site. When the number of trips originating from a zone divided by the population of that zone is the dependent variable, it is termed the zonal travel cost model (ZTCM). The ZTCM has been popular in cultural economics since the early valuations of heritage sites by Martin (1994) and Poor and Smith (2004). It is used when multiple individual visits

\footnotetext{
1 The few attempts to compare the results of stated and revealed preference valuation methods for the same cultural goods show that the estimates were of the same order of magnitude. For example, Martin (1994) observes a willingness to pay (WTP) of US\$7.95 per year per inhabitant of Quebec to support all the museums in the city and US\$8.39 of CS per visitor to the Musee de la Civilisation in Quebec, based on travel cost valuation. Armbrecht (2014) compared the results of contingent and travel cost valuations for the Nordic Watercolour Museum in Sweden. The aggregated WTP from the contingent valuation study of 5.96 million EUR was comparable with the total WTP (CS plus travel costs and entrance fees) of 5.10 million EUR; the difference was interpreted as stemming from the passive use value.
} 
are infrequent. The observation of trips by individual users of a site is called the individual travel cost model (ITC); this provides more precise results and enables a more detailed analysis of the socio-demographic characteristics of visitors (Brida et al. 2012b). The second type of travel cost models is site choice models, although they are more challenging in terms of data collection; these analyse the potential visitor's choice of where to go on a particular trip. All models enable the estimation of the use value of cultural sites.

The non-market valuation of museums has received the broadest interest in the literature. While most studies were conducted using stated preference-based methods, the newest revision of museum valuations (Bakhshi et al. 2015) indicates a few attempts to use travel cost data. Brida, Meleddu, and Pulina examined the relationship between repeated visits and distance to the site, as well as other costs related to the visit (e.g. beverage expenses, shopping in the city) for visitors of the Contemporary and Modern Art Museum of Trento and Rovereto (2012a) and South Tyrol's Museum of Archaeology in the Autonomous Province of Bolzano (2012b). In both cases, the zero-truncated Poisson model was employed for the ITC framework. As the aim of the study was to specify correlates of repeat visitation, the CS from a visit was not obtained. Authors observed a negative relationship between the expected number of visits and the distance from the museum in Rovereto. On the contrary, in a study concentrating on a museum in Bolzano, travel costs and other related expenses (e.g. beverage expenses, shopping in the city) had a positive effect on repeated visits. The authors explained this finding with the idea that visiting a cultural attraction may be regarded as an escape from daily routines; therefore, the longer the distance, the better the visit serves the visitors' goals. Melstrom (2015) confirms the intuitive result that travel costs have a negative impact on the number of trips for the case study of the Cowpens National Battlefield in the USA. The ITC model was applied; it was noted that substitute prices had a significant effect (in particular, visitors with low travel costs to substitute venues visited the Cowpens Battlefield less frequently). The estimates of CS (\$12 per trip) are in line with the results for similar sites (Melstrom 2014). All of these articles were single-site studies.

Only a few articles examining the non-market value of theatres have been published so far, most of which use stated preference techniques (Bille Hansen 1997; Grisolía and Willis 2011; Willis and Snowball 2009; Wiśniewska and Czajkowski 2017). Revealed preference data and the travel cost technique were employed in two articles: Forrest et al. (2000) applied a ZTCM to the audience data of the Royal Exchange Theatre in Manchester, UK, that had been collected on-site over the course of a week. They observed a benefit-to-cost ratio of 1.33, where costs represent a weekly subsidy the theatre receives. One of the limitations highlighted in the study is the omission of the prices of substitutes in the demand equation and, ancillary to that, the substitutability of a visit to the Royal Exchange Theatre with attendance at any other show at a theatre of a similar distance from the respondent's home; this limitation would, however, be more severe in the case of institutions situated in denser cultural centres like London. Willis et al. (2012) employ count data models to estimate the determinants of the value of the regional theatre in Newcastle upon Tyne using booking data for the season 2008/2009. Depending on the model employed, the estimated use value either just exceeds the subsidy received by the 
theatre or falls short by approximately one-third. The results are very sensitive to the socio-demographic characteristics of the population, which have a stronger influence on attendance than distance from the theatre. ${ }^{2}$ Even a small increase in the proportion of younger or older people and a (connected) decrease in the proportion of households with dependent children, in addition to a higher proportion of economically inactive people or those who are in professional or managerial occupations, would significantly increase ticket sales and CS and decrease the subsidy required. The result is also driven by the fact that the theatre does not have a close substitute in the nearby towns.

To the best of our knowledge, the only non-market valuation study of movies is Bégin et al. (2000), who focused on the willingness to pay of the French and the French Canadians to support the national film industry. The preferences stated by a limited number of moviegoers reveal their satisfaction with the current level of contributions to the film industry in Quebec and a willingness to pay additional tax to increase its support in France. The reason for this limited amount of research in the field undoubtedly lies in the more industrial organisation of this branch of culture. The few non-market valuations of movies are followed by a small number of valuations of television broadcasting, mostly using stated preferences (Bohm 1974; Papandrea 1999; Schwer and Daneshvary 1995).

Most of the studies are limited to the valuation of a single site. Members of a society can have difficulties identifying the value of a particular item that is embedded within similar things (e.g. a museum among other museums) (Kahneman and Knetsch 1992). The same phenomenon occurs with a wider selection of goods that share similar features (e.g. items belonging to the cultural sector). This problem of 'embedding' was indicated indirectly in cited studies where the availability of substitution was highlighted as a vital factor for the estimates. The effect applies mostly to stated preference-based methods (Carson and Mitchell 1995, Carson et al. 1998); however, revealed preference-based techniques such as the travel cost method have also been criticised for disregarding the possibility of substitutes in single-site valuation studies (Fletcher et al. 1990).

Boter et al. (2005) refer to the embedding effect in their article representing the first application of a site choice model in cultural economics: '[if] estimates of social value are to represent realistic values, one needs to introduce choice options in the measurement process, especially since choosing among complementary or substitute alternatives is an important aspect of consumers' valuation of cultural goods'. They employ a site choice model to compare the relative value of multiple competing cultural organisations: 108 Dutch museums. Using revealed preference data (the visiting behaviour of holders of the Dutch National Museum Card; the cost of travel to the museum visited), they identified the value of each museum in relation to one other arbitrarily chosen museum. The results could help to justify the distribution of limited resources among the institutions concerned. A limited number of other

\footnotetext{
2 The ambiguous impact of costs on demand is a well-known phenomenon in the economics of performing arts. For example, Throsby (1990) finds price coefficients to be insignificant to demand for two out of three investigated theatres, with an unexpected (positive) sign in the remaining one.
} 
applications of revealed preference-based research on cultural institutions include a variety of venues (just four cultural heritage sites in Bedate et al. 2004; two museums in Bakhshi et al. 2015). There is also a lack of studies employing these nonmarket valuation techniques to evaluate more than one kind of cultural institution; the only example of which we are aware is the comparison of a concert hall and a museum in Armbrecht (2014). Therefore, this study, with its aim of evaluating the entire cultural market of a given city, advances far beyond the current state of research.

\section{Case study and data}

The data used in this study were gathered in a survey conducted by a professional public opinion survey firm in February and March 2014. The representative sample of 1699 inhabitants of Warsaw over 18 years of age was quota-controlled with respect to gender, age, and education. ${ }^{3,4}$

The sample includes both individuals who visited and who did not visit cultural institutions in the year before the survey was conducted. Respondents provided information about the number of trips they took in the past 12 months to three types of cultural institution in Warsaw: museums, theatres, and cinemas. They were also asked about additional details regarding their last visit, such as the name of the institution they visited and the ticket price. ${ }^{5}$ As we have detailed data only about the last visit individuals made, we assume that subsequent choices made by individuals are independent of each other; for example, the fact that an individual chose to visit a given theatre before does not make him more or less likely to visit the same theatre again (conditional on his preferences). The order of the sets of questions regarding the individual's last visit to one of the three types of institutions was randomised across respondents.

According to the information about number of trips and their last visit to a cultural venue, we identified three samples in the study: museum-goers (1060 observations), theatre-goers (1322 observations), and cinema-goers (1430 observations). These samples include individuals who have visited a given type of venue at least once during 12 months prior to filling in the survey and who provided the name of the venue chosen for their last visit. Clearly, some individuals have visited more than one type of the cultural venue, so there is an overlap between samples.

The inhabitants of Warsaw indicated 28 museums, 43 theatres, and 24 cinemas in the city, all of which have been visited by at least one of the respondents in the

\footnotetext{
3 The online supplement to our paper, available at http://czaj.org/research/supplementarymaterials, includes survey questionnaire, data, and software codes for estimating the specific models used in this study, as well as appendices with additional information.

4 The sample and population characteristics are summarised in Table A2.1 in Online Appendix A, available in the online supplement to our paper.

${ }^{5}$ Using a general population survey, rather than on-site sampling, allows us to avoid unrepresentative samples and self-selection bias. The questions from the survey, which are the basis of this research, are detailed in Online Appendix A.
} 
Table 1 Cultural institutions in Warsaw in 2013

\begin{tabular}{llcll}
\hline & Total & Public & $\begin{array}{l}\text { Average ticket } \\
\text { price (EUR) }\end{array}$ & $\begin{array}{l}\text { Subsidy } \\
\text { received } \\
(\text { EUR) }\end{array}$ \\
\hline Museums & 28 & 27 & 3.19 & $60,672,274$ \\
Theatres & 43 & 26 & 15.63 & $55,877,750$ \\
Cinemas & 24 & 7 & 5.62 & - \\
\hline
\end{tabular}

${ }^{\mathrm{a}}$ We hereinafter assume that the EUR/PLN exchange rate $=4.197642$ (the average exchange rate from daily quotes in 2013 by the National Bank of Poland)

year prior to the survey being conducted. The pilot version of the survey contained an open question, where respondents could have indicated an institution they visited. Once indicated as visited, the institution was incorporated into the closed list used in the main part of the survey. We therefore followed visitors' choices of museums, theatres, and cinemas, while assuming that the inhabitants of Warsaw would be familiar with them.

Table 1 presents the basic information about the institutions to be valued. They differ in terms of ownership and engagement with public support. ${ }^{6}$

Museums in Poland are highly dependent on public funding. They are obliged to allow access to their exhibitions for free at least once a week (the average entrance fee for the other days in 2013 was 3.19 EUR). Museums receive the highest level of public support, although it is divided among many venues as all but two of the museums are public. The average proportion of public support in the budgets of local museums in Poland is $81 \%$ (Narodowe Centrum Kultury 2016). Museums specialise in presenting a range of fields of human activity, including art, social and political history, and science.

The average ticket price for a performing arts piece is equal to $15.63 \mathrm{EUR}$; however, there is a big difference between institutions run by non-governmental organisation (NGO) (about 12 EUR on average), public theatres (about 15 EUR on average), and private theatres (nearly 22 EUR on average); furthermore, discounted tickets are available. Even the largest theatres are unable to seat 1000 people in the audience. About half of the theatres ( 25 venues) that are run by the government received nearly all of the public support available to them. There are wide discrepancies in terms of the value of the support: the richest theatre receives $33 \%$ of the whole amount, while the next richest receives just 10\%. The Warsaw theatre market is very diverse: it includes the largest musical theatre productions in the country, internationally famous experimental stages, national theatres, small children's theatres, and many sites that perform dramas approachable by the local community. The offerings of one theatre could be treated as substitutes for performances in another,

\footnotetext{
${ }^{6}$ Hereinafter we refer to public statistics from 2013 as the most relevant for survey data revealing respondents' cultural participation mostly in this year.
} 
at least among institutions with similar repertoires (for a description of the theatre market in Poland and Warsaw, see Fernández-Blanco et al. 2018).

Cinemas have significant entry fees-albeit they are three times cheaper than a theatre ticket-and limited problems with congestion. Although the market primarily consists of private institutions, there are two cinemas owned by public bodies and leased to private entrepreneurs, and a few others that are part of larger public institutions. As a result, it is impossible to estimate the public subsidies they receive. It is vital to note that private ownership does not prevent a cinema from providing public benefits. At least from the European perspective, movie productions and performances deserve public support just as much as other cultural products and services. By treating movies as art rather than entertainment, movie providers can pursue the non-profit objectives also shared by film producers (McKenzie 2012). Indeed, $60 \%$ of the institutions belong to the Arthouse Cinemas Network (many of which are private), which means that a public body (the National Film Archive) has acknowledged their special artistic and educational value and provides financial support for the distribution of these films, as well as educational activities targeted at younger audiences. The Polish film industry, similarly to its German counterpart, is an industry in which heavy public funding is employed to maintain a small domestic market (Jansen 2005). The average ticket price in cinemas belonging to the Arthouse Cinemas Network (4.95 EUR) is substantially lower than in multiplexes (7.15 EUR).

Compared to data from official statistics, the results of the survey reveal that the number of visits is slightly higher in the case of theatre and lower for museums and cinemas. These differences may be explained on the basis of the unequal attention paid to each type of cultural institution in the survey. Specifically, the first section of the questionnaire introduced Warsaw's theatre market and encouraged respondents to reflect on their theatrical preferences. Consequently, we encounter one of the common problems of surveying: the so-called social desirability bias (Couch and Keniston 1961; DeMaio 1984; Sellitz et al. 1963, Groves et al. 2009; Schuman and Presser 1996). This refers to the tendency to present a favourable picture of oneself in one's own perspective, the perspective of the interviewer, or of society as a whole. Knowing that theatre is a major point of interest of the survey, respondents recognised that going to the theatre was a behavioural trait favoured by the authors of the survey, and were incentivised to shape their responses accordingly. Moreover, while theatre remains a part of the traditionally defined high arts (which is not necessarily the case for cinemas and at least some types of museums), belonging to the class of theatre-goers appears to be desirable and deserving of social approval (Schwarz and Sudman 1992). We weighted the results according to official statistics to overcome the problem of social desirability. ${ }^{7}$ Moreover, we considered the proportion of

\footnotetext{
7 The Central Statistical Office of Poland provides information about the number of visits to museums, theatres, and cinemas in relation to the population at the regional level. Additionally, the number of visits to museums is given at the local level. $91 \%$ of visitors to museums in the Masovian district consist of museum-goers in Warsaw. We used this proportion to count the number of theatre-goers and cinemagoers in Warsaw.
} 
guests from outside the city reported by museums (e.g. see: Muzeum Narodowe w Warszawie 2016) and scaled the result accordingly. In the end, the weights we used were 1.85 for museums, 0.72 for theatres, and 1.26 for cinemas.

The mean (official statistics-corrected) annual number of trips was 3.61 for museums, 2.14 for theatres, and 5.37 for cinemas. We observed large differences in the frequency of choosing different venues. For museums, the number of visits ranged from 1 to 250; for theatres, from 1 to over 90; and for cinemas, from 1 to 185 . The distribution of trips among specific institutions was the most uniform among theatres, while in the case of museums we observe the 'superstar' effect: several museums attracted a very large number of visits. In the case of cinemas, as expected, large multiplexes with many movie rooms attracted more visitors. ${ }^{8}$

\section{Methods}

The econometric framework we follow was proposed by Hausman et al. (1995). In the two-stage budgeting model, an individual first decides how many visits to make to a given type of cultural institution (a museum, theatre, or cinema); he or she then decides how to allocate these trips across the available institutions. ${ }^{9}$ The first step is modelled using a count data model and the second using a discrete choice model. Linking these two components has been a best practice approach for the estimation of recreational values since the publication of the seminal paper by Bockstael et al. (1987)..$^{10}$

Formally, the model can be described as follows: At the second stage, an individual $i$ chooses between visiting one of $J$ the available cultural institutions of a given type in such a way that maximises his utility function

$$
U_{i j}=\alpha_{j}-\beta C_{i j}+\varepsilon_{i j}
$$

where $\alpha_{j}$ is an alternative specific constant for alternative $j, j \in\{1, \ldots, J\}$ ( $\alpha_{1}$ was constrained to 0 and therefore used as a reference level). ${ }^{11}$ The inclusion of all possible alternative specific constants makes it impossible to estimate the effects of some institution-specific characteristics, but this approach allows us to control for all of the possible differences between institutions, including the unobserved ones (Murdock 2006). $C_{i j}$ represents the cost incurred by the individual, which is a sum of two components: ticket price and travel cost. In the case of an institution that an individual has actually visited, we used the ticket prices reported in the survey. For other institutions, the ticket price was taken from the description on the website of each

\footnotetext{
8 Tables A2.2, A2.3, and A2.4 in Online Appendix A present the descriptive statistics for all the other variables used in the study for all four samples analysed.

9 We estimate separate models for each type of cultural institution.

10 See Parsons et al. (1999) for a discussion and comparison with other approaches.

11 At this stage, we use observations only from individuals who have visited at least one institution in the last year. We assume that if an individual decided not to make any trips in the first stage, they have nothing to allocate in the second stage.
} 
institution. ${ }^{12}$ In our analysis, we assumed that travel cost consists of vehicle operating costs and the opportunity cost of the respondent's leisure time. The distance to travel was calculated with the use of Google Maps (the shortest road route between two places: the theatre and the location of the respondent's home, identified by the zip code provided in their response to the survey), which was then multiplied by the average official reimbursement rate for the cost of driving in Poland (0.4637 PLN/ $\mathrm{km})$. The travel time was estimated based on the distance between a respondent and a theatre and subsequently multiplied by one-third of the average hourly wage (Gürlük and Rehber 2008; Huhtala and Lankia 2012). Finally, $\varepsilon_{i j}$ is a stochastic term following extreme value distribution, which leads to the well-known multinomial logit formula of the likelihood function:

$$
L_{i}=\sum_{j=1}^{J} y_{i j} \frac{\exp \left(\alpha_{j}-\beta C_{i j}\right)}{\sum \exp \left(\alpha_{l}-\beta C_{i l}\right)},
$$

where $y_{i j}$ is equal to 1 if an individual $i$ has chosen alternative $j$ and 0 otherwise.

Following Hausman et al. (1995), we define the inclusive value of an individual $i$ as

$$
I V_{i}=\mathbf{E}\left(U_{i}\right)=\log \left(\sum_{j=1}^{J} \exp \left(\alpha_{j}-\beta C_{i j}\right)\right),
$$

which corresponds to the expected utility from the choice situation. This framework can then be used to calculate the per-visit CS using the following equation:

$$
S_{i}=\frac{I V_{i}}{\beta} .
$$

Next, in order to obtain institution-specific welfare estimates, we follow the approach detailed by Termansen et al. (2013). The per-visit CS when access to the $k$ th cultural institution is lost can be calculated as:

$$
S_{i k}^{*}=\frac{1}{\beta} \log \left(\sum_{\substack{j=0 \\ j \neq k}}^{J} \exp \left(\alpha_{j}-\beta C_{i j}\right)\right) .
$$

This is equivalent to assuming that the cost for visiting the $k$ th cultural institution becomes infinitely large. The loss of welfare due to the loss of access to the $k$ th institution is then given as $S_{i}-S_{i k}^{*}$. Analogous calculations can be made for any subset of cultural institutions (for example all public theatres).

In the first stage of the budgeting model, an individual decides how many visits to make to a given type of cultural institution. This decision depends on the vector of

\footnotetext{
12 In the case of museums, we used the price of a normal ticket for paid entrance as the average price. We calculated average ticket prices for theatres using information about the prices for performances played on the biggest stage with weights equal to the fraction of seats to be sold at each price. For cinemas, this is the price of a normal ticket for the evening screening for adults.
} 
individual characteristics $\mathbf{X}_{i}$ and the price index. Following Hausman et al. (1995), we employ a per-trip CS, $S_{i}$ [see Eq. (4)] as a price index, and assume that the mean number of trips is given as:

$$
\lambda_{i}=\exp \left(\mathbf{X}_{i} \boldsymbol{\tau}+\phi S_{i}\right) .
$$

The number of trips, $T_{i}$, is then modelled using the negative binomial $\mathrm{P}$ model (NBP; Greene 2008), in which the probability of observing $t$ trips is given using:

$$
P\left(T_{i}=t\right)=\frac{\Gamma\left(\theta \lambda_{i}^{Q}+t\right)}{\Gamma\left(\theta \lambda_{i}^{Q}\right) t !} u_{i}^{\theta \lambda_{i}^{Q}}\left(1-u_{i}\right)^{t}
$$

where $u_{i}=\frac{\theta \lambda_{i}^{Q}}{\theta \lambda_{i}^{Q}+\lambda_{i}} . \theta$ and $P=2-Q$ are the parameters to be estimated; when $P=2$, the model collapses to the standard negative binomial regression.

Estimating the total CS requires integrating the demand function over the price index:

$$
C S_{i}=\int_{-\infty}^{S_{i}} \exp \left(\mathbf{X}_{i} \boldsymbol{\tau}+\phi s_{i}\right) d s_{i}=\frac{\exp \left(\mathbf{X}_{i} \boldsymbol{\tau}\right) \exp \left(\phi S_{i}\right)}{\phi}=\frac{\lambda_{i}}{\phi}
$$

The resulting total change in the CS related to the loss of access to the $k$ th cultural institution can be calculated as:

$$
\Delta_{k} C S_{i}=\frac{1}{\phi} \exp \left(\mathbf{X}_{i} \boldsymbol{\tau}\right)\left[\exp \left(\phi S_{i}\right)-\exp \left(\phi S_{i k}^{*}\right)\right]
$$

As we mentioned at the beginning of this section, we use weights to correct for the discrepancy between the number of trips by individuals reported in the survey conducted in the current research and the official statistics. As both formulas in Eqs. (8) and (9) depend on the predicted number of trips $\left(\lambda_{i}\right)$, we adjusted these numbers by multiplying them by the weights for each type of cultural institution.

The welfare measures presented in Eqs. (8) and (9) are individual specific. Consequently, we present only values averaged over all individuals. In order to obtain the standard errors of our estimates, we used the delta method.

\section{Results}

\subsection{Site choice model}

We first estimate the site choice model as described in Sect. $4 .^{13}$ In the twostage budgeting model, the site choice model constitutes a second stage in which

\footnotetext{
13 The models presented here were estimated using a DCE package developed in MATLAB and avail-
} able at https://github.com/czaj/DCE. 
Table 2 Results of the site choice models

\begin{tabular}{llll}
\hline & Museum & Theatre & Cinema \\
\hline $\begin{array}{l}\text { Total Cost (in 100 PLN) } \\
\text { Model diagnostics }\end{array}$ & $-8.8457 * * *(0.4945)$ & $-9.5087^{* * *}(0.2515)$ & $-17.4697 * * *(0.4811)$ \\
LL at convergence & -2546.553 & -3666.281 & -2932.1693 \\
${\text { McFadden's pseudo- }{ }^{2}}^{2}$ & 0.0603 & 0.1918 & 0.2557 \\
Ben-Akiva-Lerman's pseudo- & 0.2171 & 0.2519 & 0.303 \\
$\quad \mathrm{R}^{2}$ & & & \\
AIC/n & 4.8576 & 5.6116 & 4.1345 \\
BIC/n & 4.9888 & 5.7803 & 4.2229 \\
$n$ (observations) & 1060 & 1322 & 1430 \\
$k$ (parameters) & 28 & 43 & 24 \\
\hline
\end{tabular}

Asterisks indicate significance levels $(* * * 1 \%, * * 5 \%, * 10 \%)$

respondents allocate the chosen number of trips from the first stage between the available sites. Nevertheless, from the researchers' perspective, the site choice model needs to be estimated first in order to obtain the price index [consult Eq. (4)], which will provide a link between both stages of the procedure. We estimate the multinomial logit model, for which a dependent variable indicates which site individual visited in his or her last trip. Specifically, it is equal to 1 for a visited site, and it is equal to 0 for all the other sites. As in the available dataset we do not have detailed information regarding visits other than the last one, we have only one observation per respondent, and the sample is limited to the individuals who have visited at least one site (consult footnote 9).

Table 2 provides the results from the site choice models, which are estimated separately for different types of cultural institutions. The models for different types of institutions are estimated on different samples, as the share of respondents who visited at least one site differs between them. ${ }^{14}$ The largest sample is for cinema, which is an expected result. For brevity, we report only the coefficients for total cost $\left[C_{i j}\right.$ in Eq. (1)] and models' diagnostics. As described in Eq. (1), other coefficients in these models are alternative specific constants, which allow us to control for differences between specific sites ${ }^{15}$ For all three types of cultural institutions, total cost has a significant, negative effect, as was expected. We note that the magnitude of the coefficients cannot be compared across the models, as there may be some differences in the scale of the stochastic term in the utility specifications (which is normalised to one, in order to identify the model). Using the results of the site choice models, a price index is calculated for each of the 1699 individuals in the sample (including the ones who have not visited any sites), which is later used in the count data model.

\footnotetext{
${ }^{14}$ Consult samples of museum-goers, theatre-goers, and cinema-goers as presented in the tables in 'Sample representativeness and descriptive statistics' for Online Appendix A.

15 The results of the full model including estimated coefficients for alternative specific constants are available in Online Appendix C.
} 
Table 3 Results of the count data model for participants' number of trips to cultural institutions

\begin{tabular}{|c|c|c|c|}
\hline & Museum & Theatre & Cinema \\
\hline Constant & $0.4714 * * *$ & $0.6697 * * *$ & $1.6152 * * *$ \\
\hline CS per trip & $0.0139 * * *$ & $0.0103 * * *$ & $0.0091 * *$ \\
\hline Household income (in 10000 PLN) & $0.2479 * * *$ & $0.6956^{* * *}$ & $0.6994 * * *$ \\
\hline Middle education (base level: basic education) & $0.1500 * *$ & $0.1980^{* * *}$ & $0.1941 * * *$ \\
\hline Higher education (base level: basic education) & $0.3509 * * *$ & $0.4155^{* * *}$ & $0.4172 * * *$ \\
\hline Years living in Warsaw (in 100 years) & $-1.4239 * * *$ & $-0.7892 *$ & $-1.4737 * * *$ \\
\hline Years living in Warsaw squared (in 100 years) & $2.1393 * * *$ & $1.4970 * * *$ & $2.0898 * * *$ \\
\hline Employed & $0.1300 * *$ & $0.1379 * *$ & $0.2394 * * *$ \\
\hline Have 1 child (base level: no children) & $0.2824 * * *$ & $0.1569 * * *$ & 0.0208 \\
\hline Have 2 children (base level: no children) & -0.0126 & 0.0954 & $-0.1416^{*}$ \\
\hline Have 3 children (base level: no children) & -0.3626 & -0.0615 & -0.2557 \\
\hline 2 people in the household (base level: 1 ) & -0.0632 & & $-0.1344 *$ \\
\hline 3 people in the household (base level: 1 ) & $-0.1754^{*}$ & & $-0.1908 * *$ \\
\hline 4 people in the household (base level: 1 ) & 0.0741 & & -0.0568 \\
\hline More than 4 people in the household (base level: 1 ) & 0.1116 & & -0.0931 \\
\hline Household income squared (in 10,000 PLN) & $-0.1489 * *$ & $-0.1743 * * *$ & \\
\hline Household income not reported & $-0.1411^{* *}$ & & \\
\hline Age (in 100 years) & & & $-1.3062 * * *$ \\
\hline Born in Warsaw & & & $0.1138 *$ \\
\hline \multicolumn{4}{|l|}{ Overdispersion parameters } \\
\hline$-\log \theta$ & $1.2302 * * *$ & $1.1774 * * *$ & $1.2534 * * *$ \\
\hline$P$ & -0.2207 & $0.5216^{*}$ & $0.7326 * * *$ \\
\hline
\end{tabular}

Asterisk indicates significance levels (***1\%, **5\%,*10\%)

\subsection{Count data model}

Table 3 presents the results of the NBP models that were used to estimate the determinants of the number of trips to each type of cultural institution. ${ }^{16}$ Instead of price, the models use a price index; this is a measure of the CS per trip obtained from the site choice models, as reported in the previous subsection. The price index was calculated according to Eq. (4) and provides the link between two stages of the budgeting model. The NBP model performs better than the standard negative binomial (see parameter P). The estimated coefficients for the per-trip CS are significant and positive, ranging from 0.0091 for cinemas and 0.0139 for museums. Section 2 notes that the ticket price was identified in previous studies as an ambiguous, sometimes negligible determinant of demand for theatres and museums. Instead, our approach uses CS, which accounts for the opportunity cost of time and travel costs, leading

\footnotetext{
${ }^{16}$ Table 2 presents the results of the final models, including only statistically significant variables found separately for each type of institution. Variables such as gender or having a job related to culture (selfreported) were found to be insignificant for all types of cultural institutions and are therefore not reported in Table 3. The versions of the models including more socio-demographic characteristics are available in the online supplement.
} 
to results that are in line with economic theory and most of the literature's existing empirical results. The coefficients of CS per trip are also of similar magnitude to previous studies in the field of cultural economics, no matter how much they differ in terms of the data used and econometric models applied (Forrest et al. 2000; Martin 1994; Poor and Smith 2004). For theatres, we obtain nearly identical estimates to the only comparable study using the same model, NBP, in the same field (Willis et al. 2012).

We employed the socio-demographic characteristics of respondents as control variables. The results reveal very similar determinants of cultural participation regardless of the type of cultural institution examined. They are consistent with current studies in the performing arts economics and museum economics fields (and their associated ambiguities); for a review, see Frey and Meier (2006), Seaman (2006), and Towse (2010). There is little research regarding the socio-demographic determinants of demand in film economics (Cuadrado and Frasquet 1999), where demand is usually explained by the characteristics of the movie, reviews, and 'word of mouth' (McKenzie 2012; De Vany 2006). Therefore, our study introduces new knowledge into this underdeveloped field.

We find that income and education are important determinants of cultural participation. The coefficients for income in our models are positive and significant. However, the higher the income, the lower the increase in the number of trips, as the coefficient for household income squared is negative (result statistically significant only for theatres and cinemas). Notably, the higher the income, the higher the opportunity cost of time, which is another important determinant of leisure activities (including visiting cultural venues). We expect that respondents who did not report their income may earn less than others; therefore, the negative coefficient for unreported household income included in the model for museums informs the lower number of visits for people with implicitly lower income. The positive impact of being employed goes hand in hand with these observations: generally, having a job raises the chance of achieving higher earnings. Employment consistently influences the number of visits to any kind of cultural venue in a positive and statistically significant way. The higher the level of education, the higher the number of visits to cultural venues. The effect is stronger for higher education than for middle education in comparison with primary education. Higher educated people have the human and cultural capital available to more fully benefit from cultural participation.

Young people participate in culture more, both as part of school trips and as a result of having more free time (which is necessary to participate in time-consuming activities), as indicated by the negative coefficient for age in our model. However, the effect is statistically significant only for cinema-goers.

All the respondents in our sample are residents of Warsaw; however, as the city has rapidly grown, there are large differences in the lengths of time the residents have been living there. On the one hand, people who were born in the city could have a stronger tradition of attending local venues. On the other, someone who moves into the city explores it in their initial years and potentially loses interest later after becoming familiar with the local entertainment. The results of our model confirm this reasoning; the coefficient for being born in Warsaw is positive and significant in the model for cinemas. In general, the number of visits decreases with the number of years spent 
Table 4 Average economic use benefits associated with cultural institutions in Warsaw (in EUR per person per year, standard deviation in brackets)

\begin{tabular}{|c|c|c|c|c|c|c|}
\hline & \multicolumn{2}{|l|}{ Museums } & \multicolumn{2}{|l|}{ Theatres } & \multicolumn{2}{|l|}{ Cinemas } \\
\hline & All & Per institution & All & Per institution & All & Per institution \\
\hline Total & $62.53(16.34)$ & 0.38 & $50.45(9.87)$ & 0.15 & $148.78(64.11)$ & 0.41 \\
\hline \multicolumn{7}{|c|}{ Cultural institutions by ownership } \\
\hline Public & $32.54(2.90)$ & 0.41 & $5.77(0.15)$ & 0.16 & $0.50(0.01)$ & 0.07 \\
\hline Private & - & - & $1.15(0.03)$ & 0.14 & $20.89(0.83)$ & 0.58 \\
\hline NGO & $0.10(0.00)$ & 0.05 & $1.55(0.04)$ & 0.14 & $0.06(0.00)$ & 0.06 \\
\hline
\end{tabular}

in the city, but this tendency changes after quite a long period of living in Warsaw: the number of visits to museums, theatres, and cinemas starts to grow when an inhabitant exceeds 32, 26, and 36 years of living in Warsaw, respectively. Note that this result is obtained while controlling for the age of the respondent.

The number of children (connected with the size of the household) is also found to determine participation in culture. Although the direction of the impact depends on the number of children, in general, having children encourages people to visit cultural venues, particularly museums that deliver educational services, and theatres which are still recognised as, so-called, high culture. However, having children limits free time and raises household expenditure, which we can observe from the negative and significant coefficient for having two children (in comparison with childlessness) in the model for cinemas.

We conducted a number of robustness checks. Specifically, we used a distinct approach to approximate ticket prices. The models reported in this section use average ticket prices for all of the institutions except for the institution that the individual visited last. For this institution, we use self-reported ticket prices (consult footnote 8 for details). As a robustness check, we created indices of relative price differences between each pair of institutions of a given type and then use them to approximate ticket prices. For example, if an individual visited theatre A, and the calculated index indicates that, on average, ticket prices in theatre B are $25 \%$ higher than in theatre $\mathrm{A}$, we use the self-reported ticket price for theatre A, multiplied by 1.25 as an approximation of ticket prices in theatre B. Such an approach could take into account the fact that some individuals may buy more expensive tickets (e.g. better seats) than the average visitor to different institutions. We find that using this approach leads to a higher total CS for theatres, but a lower one for cinemas. ${ }^{17}$ The differences are nonetheless within the confidence intervals of the estimates presented in Table 4 (see below). Choice models estimated with total cost generated this way have nonetheless worse fit to data than models reported in Table 2 (BIC/n equal to 6.23 and 4.74 for theatres and cinemas, respectively).

\footnotetext{
17 We did not conduct a similar analysis for museums, as calculated relative differences in prices were not particularly useful, due to there being free entry to several institutions in Warsaw.
} 


\subsection{Economic benefit estimates}

The estimates of benefits associated with various cultural institutions are displayed in Table 4. The total value is calculated according to Eq. (8) and then averaged over the individual participants. The values per institution are calculated by employing Eq. (9) for each institution and then averaging them over both the number of institutions and the number of individuals. The values per institution therefore indicate how much each individual's CS would, on average, decrease if one site of a given type (e.g. museum) would be closed. The relationship between total value and value per institution is not linear. With the loss of access to a single site, there are typically many possible substitutes. The lack of access to the whole market is more 'unpleasant' than the net effect of the lost access to particular sites taken individually. In the second part of Table 4, the same calculation is repeated for different types of ownership structure.

All results are given for institutions that are at least indirectly supported by the public sector. As the access cost includes ticket prices, the estimates correspond to the current level of public engagement in supporting culture. In addition, because we incorporated travel costs into the implicit price of access to cultural institutions, the estimated number of visits and CS can change if new transportation alternatives are developed. Nonetheless, the estimates provide a snapshot of the benefits associated with each type of cultural institution, assuming the current market conditions remain constant.

Cinemas - the smallest group of institutions in our data-create the highest use benefits, with an annual CS per individual of approximately 149 EUR. This means that an average Warsaw citizen would be willing to pay 149 EUR per year for access to cinemas in Warsaw (on top of travel and ticket costs). To the best of our knowledge, this is the first such estimate in the economics of cinemas. This value exceeds the estimated benefits associated with having access to theatres (50.45 EUR) and museums (62.653 EUR). On a per-institution basis, closing a single cinema would make an average citizen 0.41 EUR per year worse off, with equivalent values in an average theatre or museum estimated at 0.15 EUR and 0.38 EUR, respectively.

The results for museums, being less than 1 EUR annually per person per institution, are significantly lower in comparison with previous studies based on travel cost data: about 5 USD per visitor of Musée de la civilisation in Québec (Martin 1994), 12 USD per trip to a battlefield in the USA (Melstrom 2014, 2015), between 8 USD and 19 USD annually per visitor of the St. Mary's City, an historical archaeological site (Poor and Smith 2004). Similar results are obtained in cases where theatres are compared with the estimates of CS for visiting a performance in the Royal Exchange Theatre in Manchester-about 8 GBP (Forrest et al. 2000) or the Northern Stage in Newcastle upon Tyne-20-30 GBP depending on the model employed (Willis et al. 2012). Notably, these results come from single-site valuation studies that can suffer from the embedding effect and a tendency to not account for the presence of substitutes. Assuming that the chosen sites in the studies cited encompass most of the local cultural markets of a given cultural service, our calculation of CS relative to access to the whole cultural market would turn out to be of the same magnitude as the estimates present in the literature. 
Table 5 Aggregated total CS and total subsidies for cultural institutions (EUR per year; 2013)

\begin{tabular}{llll}
\hline & Museums & Theatres & Cinemas \\
\hline Aggregated CS & $90,576,222$ & $73,067,810$ & $215,502,853$ \\
Aggregated subsidy & $60,672,274$ & $55,877,750$ & - \\
\hline
\end{tabular}

In addition, as different cultural markets in Warsaw are organised in various ways, we estimated the benefits according to ownership structure. These results show that publicly owned museums (comprising more than $90 \%$ of the market) and theatres (comprising little more than half of the market) are valued higher as a group than those that are privately owned or NGO owned. In the case of cinemas, this relationship is reversed. In fact, while 17 out of 24 cinemas in Warsaw are privately owned, they generate substantially more benefits for consumers, both on a per-site basis and overall. This is likely the result of private cinemas being much larger and typically incorporating multiple screening rooms, although it may also reflect the higher quality of service.

Finally, for the types of institutions with diverse ownership like theatres and cinemas, we can investigate which types of ownership dominate the top and bottom rankings based on CS estimates for single sites. ${ }^{18}$ In the case of theatres, we observe a slight dominance of public institutions in the top ten and a slight dominance of NGOs in the bottom ten positions. However, it is nearly impossible to discern a stable pattern between the top or bottom rankings and ownership. However, it is much clearer for cinemas, where the top ten institutions consist of private institutions and the bottom ten consist of mostly public ones.

\section{Cost-benefit analysis and policy implications}

The comparison of the annual aggregated benefits for all inhabitants of Warsaw with subsidies awarded to cultural institutions provides new insights into the cost-benefit relationship and some implications for the formulation of policies. Aggregated CS for the cultural markets of museums, theatres, and cinemas corresponds to the estimated benefits per person multiplied by the number of adult (individuals over 18 years old) inhabitants of Warsaw (i.e. 1,448,444). This result can be interpreted as the total economic benefit gained by society from the use of its cultural market. The aggregated data are presented in Table 5.

We find that cinemas provide the largest aggregate use benefits (more than 215 million EUR per year). The loss of access to the market of theatres and museums is valued at significantly less (about 73 million EUR and 90 million EUR, respectively).

The value of aggregated subsidies comes from local, regional, and national budgetary reports for 2013 and is a sum of the direct subsidies devoted to public institutions included in the research. It therefore does not include indirect support such as that received by cinemas through the distribution channels of Arthouse Cinemas Network.

${ }^{18}$ A ranking of CS for all cultural institutions included in this research and indicated ownership is available as Online Appendix D. 
Public support for cultural institutions greatly depends on the structure of ownership within the markets; public institutions, and the markets dominated by them, are publicly supported. Similarly, numerous public museums (26) and theatres (25) receive substantial subsidies (over 60 million EUR and over 55 million EUR, respectively).

The benefit-subsidy relationship within cultural markets is similar for museums and theatres. The aggregated CS is higher than the subsidies received by both types of cultural institutions. The aggregated CS exceeds subsidies by about 20-30 million EUR, what equals to about $23-33 \%$ of the estimated benefits. This result may indicate that if the use value was the only evaluation criterion, in the case of both markets it is high enough to justify subsidies. On the other hand, cinemas, which generate the largest benefits, receive nearly no support.

The distribution of support between the two subsidised sectors is relatively equal (about 56 million EUR for theatres vs. about 61 million EUR for museums) what is in line with estimated benefits gained by the society from their accessibility (again, with dominance of museums). According to the results, there is still a room for increase in subsidies in both sectors. The inequality appears when we compare markets in the cultural sector with donations (museums and theatres) to those without them (cinemas). Cinemas, mostly excluded from the circulation of direct public support, deliver nearly three times more use benefits than theatres and twice than museums. These results raise the question about the division of subsidies between cultural sectors.

The problem of dividing public support can also be taken to a lower level and considered for individual institutions. Online Appendix B presents the rankings of museums and theatres according to the benefits and subsidies they receive. Only public venues are included. ${ }^{19}$ The overall result is that the subsidies received are not aligned with the use benefits created. Only the five museums generate use benefits that exceed the subsidies they receive. First two of them in the ranking are the newest, most modern venues in the city: superstars in the sector. The third one, Zachęta, is one of the bestknown art galleries in Poland. Among theatres, only the closure of Komedia, which is purely an entertainment theatre, would cause loss in terms of greater use benefits compared to its received subsidies. Another entertainment theatre (Kwadrat) and one of the musical theatres (Jana Kiepury) deliver benefits high enough to cover approximately $80 \%$ of its subsidies. In the case of a few venues, aggregated CS is equal to roughly $26 \%$ to $36 \%$ of the subsidy. This includes theatres with different characteristics: Ateneum and $\mathrm{Na}$ Woli, which largely deliver classical dramas challenging enough not to be classified as entertainment, but that are accessible to a broad segment of the public; Lalka, one of the theatres for children; Ochoty, a small venue with mostly educational aims; and Rampa which provides a diverse repertoire of musicals, comedies, and more challenging dramas. Overall, for the vast majority of the institutions, the subsidies they receive are much higher than the use value associated with their existence.

All investigated institutions-public, private, and NGO owned-generate value from providing access to cultural goods. However, not all are subsidised. The issue

\footnotetext{
19 Four museums and one theatre are excluded from Table B1 in Online Appendix B, as it was not possible to gather information about the subsidies they receive, partly due to the fact that they are parts of bigger institutions and official reports do not deliver detailed financial information.
} 
of cultural policy lies in its division of resources, which in particular omits entire private and NGO sectors that participate in the markets as equal (sometimes even more attractive for visitors) cultural institutions. The choice of cultural markets to be supported in Warsaw does not seem to follow simple use value estimates based on peoples' revealed preferences. As assumed, it lies rather in historical, political, and legal dependencies. However, the division of subsidies within the subsidised sectors described in this paper shows that the decisions of policy-makers are consistent with people's preferences towards the access to cultural sites. Nonetheless, even within subsidised sectors most of the individual institutions receive the support incomparably lower or higher than the use benefits delivered. Division of subsidies within these sectors needs to follow other rules than estimates of the use value. It can lie, for instance, in negotiating power of managers or the recognition of costs of services' provision instead of benefits delivery.

There is one important limitation of the comparison presented here that needs to be reiterated. The estimated economic benefits associated with use value do not constitute the total economic value of a good. There may be reasons unrelated to use as to why people may be willing to pay for a good, for example reasons associated with its existence, availability to others, or bequest value. These considerations are not reflected in consumers' market behaviour and so are not possible to capture using the visitation cost-based approach; similarly, they are not included in the estimated use-related benefits presented here. Although the distribution of subsidies is not related to the use benefits, or even visitation rates, some institutions and specific sites may be considered by policy-makers as generating higher non-use benefits, thus justifying increased public support. Notably, museums provide preservation value derived from the simple fact that they maintain and preserve heritagethe common good. Moreover, we studied only the preferences of the inhabitants of Warsaw, despite the fact that some of the cultural institutions based in the city are famous nationwide and are visited by tourists. Their preferences should be included to capture the whole value of these venues. Notwithstanding this limitation, we argue that the cost-benefit analysis - in particular, the use of non-market economic valuations - provides a sound basis for the division and evaluation of public support.

\section{Conclusions}

In this article, we considered the accessibility of cultural institutions as a means for estimating their economic use value and contrasted these benefits with the public support they received. As institutions are the main beneficiaries of public funds for culture, our analysis explored a crucial tool for cultural policy-making.

The two-stage budgeting model for recreational sites was employed to estimate the annual use-related benefits associated with access to museums, theatres, and cinemas in Warsaw. The estimated models revealed that for all three types of cultural institutions, total cost, including travel cost, has a significant and negative, as expected, effect on the choice of cultural venue. It confirms that the use of travel cost data performs better than ticket prices, which is identified in previous studies as an ambiguous, sometimes negligible, determinant of demand for cultural sites. In the methods used in this paper, the 
estimated value is highly correlated with visitation patterns. Cinemas, therefore, which were the most frequently visited, deliver substantial benefits (more than 215 million EUR). The aggregated annual benefit associated with museums and theatres was estimated at approximately 00 and 73 million EUR, respectively.

To the best of our knowledge, this is the first study to estimate the non-market value of cinemas and is one of the rare attempts to investigate the impact of sociodemographic characteristics on cinema attendance, as provided by the results of the count data model included in the econometric procedure employed in our research. In addition, our study extends revealed preference-based non-market valuation research of cultural institutions to date, which has been dominated by single-site studies, through the assessment of the value of the entire cultural market. In doing so, it helps to overcome the embedding effect and accounts for the availability of substitutes for individual cultural venues.

The three cultural markets included in the study differ in terms of the estimated use-related benefits they provide, their ownership structure, and the subsidies some of these sites receive from public funds. By highlighting these differences, we point to the challenges that cultural policy needs to address. Public ownership used to be the main basis for the delivery of public support in not just Poland, but also other countries in continental Europe. We argue that the public ownership of cultural institutions is not enough to justify public subsidies.

Overall, our results show that the distribution of subsidies follows the distribution of use-related benefits produced by cultural institutions only regarding division of public resources between sectors traditionally supported. It does not happen in the case of non-subsidised sectors and on the level of individual institutions. Cinemas, most of which are private, are nearly excluded from the circulation of public funds, despite substantial provision of benefits to the users. Therefore, our study reveals the value of cultural institutions not considered as beneficiaries of public funds. This raises the question about the proper basis for the division of public resources. Within the directly subsidised theatre and museum markets, the vast majority of which are public, we observe an equality of support between these markets associated with relatively equal delivery of use values. Museums receiving higher subsidies then theatres provide also more use benefits. The recognition of the use value is enough to justify public expenditures for both sectors, as estimated benefits exceed costs. However, the inquiry into cost-benefit relationship on the level of individual institutions raises the question about the basis for division of public resources again. The use benefits do not match subsidies on the individual institution basis.

Overall, we note that the estimates of use value, that this article delivers an example of, do not need to be the sole determinant of public support. There are other components of total economic value such as existence, bequest, stewardship, or option value, but it is likely that the subsidy decisions of current cultural policies do not take them into account. Instead, they seem to be driven by historical inertia, largely ignoring efficiency concerns. The current distribution of public support for cultural institutions indicates a strong inequality in the attitude towards public and non-public institutions, favouring public ones. Our analysis can serve as a basis for overcoming the 'adhocism' and historical dependencies in culture financing. In the case of Warsaw, this process has already started with the latest evaluation of local 
cultural policies, in which the need for the deinstitutionalisation of the sector and openness for non-public institutions and informal initiatives has been recognised.

Acknowledgements Authors are grateful to Trine Bille and Monika Murzyn-Kupisz for careful revisions of the article, helpful comments, and advises that significantly improved the quality of this study. The authors gratefully acknowledge the support of the National Science Centre of Poland (project 2014/15/N/ HS4/01441, project 2015/19/D/HS4/01972, project 2016/21/N/HS4/02094) and the Foundation for Polish Science (FNP). MC has been supported by the Czech Science Foundation (Grant No. 19-26812X) within the EXPRO Program 'Frontiers in Energy Efficiency Economics and Modelling - FE3M'.

Funding The data collection was funded by National Science Centre of Poland (grant number: 2014/15/N/HS4/01441).

\section{Compliance with ethical standards}

Conflict of interest Authors declare that they have no conflict of interest.

Open Access This article is licensed under a Creative Commons Attribution 4.0 International License, which permits use, sharing, adaptation, distribution and reproduction in any medium or format, as long as you give appropriate credit to the original author(s) and the source, provide a link to the Creative Commons licence, and indicate if changes were made. The images or other third party material in this article are included in the article's Creative Commons licence, unless indicated otherwise in a credit line to the material. If material is not included in the article's Creative Commons licence and your intended use is not permitted by statutory regulation or exceeds the permitted use, you will need to obtain permission directly from the copyright holder. To view a copy of this licence, visit http://creativecommons.org/licen ses/by/4.0/.

\section{References}

Angelini, F., \& Castellani, M. (2018). Cultural and economic value: A critical review. Journal of Cultural Economics. https://doi.org/10.1007/s10824-018-9334-4.

Armbrecht, J. (2014). Use value of cultural experiences: A comparison of contingent valuation and travel cost. Tourism Management, 42, 141-148.

Bakhshi, H., Fujiwara, D., Lawton, R., Mourato, S., \& Dolan, P. (2015). Measuring ecnomic value in cultural institutions. Wiltshire: Swindon.

Bedate, A., Herrero, L. C., \& Sanz, J. Á. (2004). Economic valuation of the cultural heritage: Application to four case studies in Spain. Journal of Cultural Heritage, 5(1), 101-111.

Bégin, D., Colbert, F., \& Dupré, R. (2000). Comparative analysis of French and French-Canadian Willingness to support the national film industry. International Journal of Cultural Policy, 7(2), 355-368.

Behr, A., Brennan, M., \& Cloonan, M. (2016). Cultural value and cultural policy: Some evidence from the world of live music. International Journal of Cultural Policy, 22(3), 403-418.

Bertacchini, E. E., Dalle Nogare, C., \& Scuderi, R. (2018). Ownership, organization structure and public service provision: the case of museums. Journal of Cultural Economics, 42(4), 619-643.

Bille Hansen, T. (1997). The willingness-to-pay for the royal theatre in Copenhagen as a public good. Journal of Cultural Economics, 21(1), 1-28.

Bockstael, N. E., Hanemann, W. M., \& Kling, C. L. (1987). Estimating the value of water quality improvements in a recreational demand framework. Water Resources Research, 29, 19-33.

Bohm, P. (1974). Estimating demand for public goods: An experiment. European Economic Review, 3, 111-130.

Boter, J., Rouwendal, J., \& Wedel, M. (2005). Employing travel time to compare the value of competing cultural organizations. Journal of Cultural Economics, 29(1), 19-33. 
Brida, J. G., Meleddu, M., \& Pulina, M. (2012a). factors influencing the intention to revisit a cultural attraction: The case study of the museum of modern and contemporary art in rovereto. Journal of Cultural Heritage, 13, 167-174.

Brida, J. G., Meleddu, M., \& Pulina, M. (2012b). Understanding urban tourism attractiveness: The case of the archaeological Ötzi Museum in Bolzano. Journal of Travel Resources, 51(6), 730-741.

Carson, R. T. (2012). Contingent valuation: A practical alternative when prices aren't available. Journal of Economic Perspectives, 26(4), 27-42.

Carson, R. T., Flores, N. E., \& Hanemann, M. W. (1998). Sequencing and valuing public goods. Journal of Environmental Economics and Management, 36, 314-324.

Carson, R. T., \& Groves, T. (2007). Incentive and informational properties of preference questions. Environmental \& Resource Economics, 37(1), 181-210.

Carson, R. T., \& Mitchell, R. C. (1995). Sequencing and nesting in contingent valuation surveys. Journal of Environmental Economics and Managements, 28, 155-173.

Couch, A., \& Keniston, K. (1961). Agreeing response set and social desirability. Journal of Abnormal and Social Psychology, 62, 175-179.

Cuadrado, M., \& Frasquet, M. (1999). Segmentation of cinema audiences: an exploratory study applied to young consumers. Journal of Cultural Economics, 23(3), 257-267.

Czajkowski, M., Vossler, C. A., Budziński, W., Wiśniewska, A., \& Zawojska, E. (2017). Addressing empirical challenges related to the incentive compatibility of stated preferences methods. Journal of Economic Behavior \& Organization, 142, 47-63.

De Vany, A. (2006). The movies. In D. Throsby \& V. Ginsburgh (Eds.), Handbook of the economics of art and culture (pp. 615-667). Amsterdam: North Holland.

DeMaio, T. J. (1984). Social desirability and survey measurement: A review. In C. F. Turner \& E. Martin (Eds.), Surveying subjective phenomena (Vol. 2, pp. 257-282). New York: Russell Sage Foundation.

Fernández-Blanco, V., Rodríguez-Álvarez, A., \& Wiśniewska, A. (2018). Measuring technical efficiency and marginal costs in the performing arts: The case of the municipal theatres of Warsaw. Journal of Cultural Economics. https://doi.org/10.1007/s10824-018-9330-8.

Fletcher, J. J., Adamowicz, W. L., \& Graham-Tomasi, T. (1990). The travel cost model of recreation demand: Theoretical and empirical issues. Leisure Sciences, 12(1), 119-147.

Forrest, D., Grime, K., \& Woods, R. (2000). Is it worth subsidising regional repertory theatre? Oxford Economic Papers, 52(2), 381-397.

Frey, B. S., \& Meier, S. (2006). The economics of museums. In D. Throsby \& V. Ginsburgh (Eds.), Handbook of the economics of art and culture (pp. 1017-1047). Amsterdam: North Holland.

Galloway, S., \& Dunlop, S. (2007). A critique of definitions of the cultural and creative industries in public policy. International Journal of Cultural Policy, 13(1), 17-31.

Greene, W. (2008). Functional forms for the negative binomial model for count data. Economics Letters, 99(3), 585-590.

Grisolía, J. M., \& Willis, K. G. (2011). An evening at the theatre: Using choice experiments to model preferences for theatres and theatrical productions. Applied Economics, 43(27), 3987-3998.

Groves, R. M., et al. (2009). Survey methodology. New York: Wiley.

Gürlük, S., \& Rehber, E. (2008). A travel cost study to estimate recreational value for a bird refuge at lake Manyas, Turkey. Journal of Environmental Management, 88(4), 1350-1360.

Hanley, N., \& Czajkowski, M. (2017). Stated preference valuation methods: An evolving tool for understanding choices and informing policy. University of Warsaw, Faculty of Economic Sciences Working Paper (1).

Hausman, J. (2012). Contingent valuation: From dubious to hopeless. Journal of Economic Perspectives, 26(4), 43-56.

Hausman, J. A., Leonard, G. K., \& McFadden, D. (1995). A utility-consistent, combined discrete choice and count data model. Assessing recreational use losses due to natural resource damage. Journal of Public Economics, 56(1), 1-30.

Hausner, J., Karwińska, A., \& Purchla, J. (Eds.). (2013). Kultura a Rozwój. Warszawa: Narodowe Centrum Kultury.

Hausner, J., Malczyk, K., Maźnica, Ł., \& Strycharz, J. (2015). Diagnoza Potencjału Podmiotów Kultury w Zakresie Realizacji Proramu Rozwoju Kultury 2020. Kraków: Fundacja GAP.

HM Treasury. (2018). The Green Book. Central Government guidance on appraisal and evaluation. London: HM Treasury.

Huhtala, A., \& Lankia, T. (2012). Valuation of trips to second homes: Do environmental attributes matter? Journal of Environmental Planning and Management, 55(6), 733-752. 
Jansen, C. (2005). The performance of german motion pictures, profits and subsidies: Some empirical evidence. Journal of Cultural Economics, 29(3), 191-212.

Kahneman, D., \& Knetsch, J. L. (1992). Valuing public goods: The purchase of moral satisfaction. Journal of Environmental Economics and Management, 22(1), 57-70.

Kling, C. L., Phaneuf, D. J., \& Zhao, J. (2012). From exxon to BP: Has some number become better than no number? Journal of Economic Perspectives, 26(4), 3-26.

Lewandowska, K. (2018). Using Isaiah Berlin's two concepts of liberty to rethink cultural policy: A case of Poland. International Journal of Cultural Policy, 24(2), 145-163.

Martin, F. (1994). Determining the size of Museum subsidies. Journal of Cultural Economics, 18(4), 255-270.

McKenzie, J. (2012). The economics of movies: A literature survey. Journal of Economic Surveys, 26(1), $42-70$.

Melstrom, R. T. (2014). Valuing historic battlefields: An application of the travel cost method to three American Civil War battlefields. Journal of Cultural Economics, 38(3), 223-236.

Melstrom, R. T. (2015). Valuing a historic site with multiple visitor types and missing survey data. Journal of Cultural Heritage, 16(1), 102-105.

Murdock, J. (2006). Handling unobserved site characteristics in random utility models of recreation demand. Journal of Environmental Economics and Management, 51(1), 1-25.

Murzyn-Kupisz, M. (2010). Cultural policy at the regional level: A decade of experiences of New Regions in Poland. Cultural Trends, 19(1-2), 65-80.

Muzeum Narodowe w Warszawie (2016). 2015: Raport Muzeum Narodowego $w$ Warszawie. Warszawa.

Narodowe Centrum Kultury. (2016). Rocznik Kultury Polskiej 2016. edited by T. Kukołowicz. Warszawa.

Navrud, S., \& Ready, R. C. (Eds.). (2002). Valuing cultural heritage. Applying environmental valuation techniques to historic buildings, monuments and artifacts. Cheltenham: Edrward Elgar.

Noonan, D. (2002). Contingent valuation studies in the arts and culture: An annotated bibliography. The Cultural Policy Center at the University of Chicago Working Paper Series.

Noonan, D. S. (2003). Contingent valuation and cultural resources: A meta-analytic review of the literature. Journal of Cultural Economics, 27, 159-176.

O'Brien, D. (2010). Measuring the value of culture: A report to the department for culture media and sport. London: Department of Culture, Media and Sport.

OECD. (2006). Cost-benefit analysis and the environment: recent developments. Paris: OECD.

Papandrea, F. (1999). Willingness to pay for domestic television programming. Journal of Cultural Economics, 23, 149-166.

Parsons, G., Jakus, P., \& Tomasi, T. (1999). A comparison of welfare estimates from four models for linking seasonal recreational trips to multinomial logit models of site choice. Journal of Environmental Economics and Management, 38(2), 143-157.

Pearce, D., Atkinson, G., \& Mourato, S. (2006). Cost-benefit analysis and the environment: recent developments (pp. 15-27). Paris: OECD.

Poor, P. J., \& Smith, J. M. (2004). Travel cost analysis of a cultural heritage site: The case of historic St. Mary's City of Maryland. Journal of Cultural Economics, 28(3), 217-229.

Schuman, H., \& Presser, S. (1996). Questions and answers in attitude surveys. Experiments on question form, wording, and context. San Diego: SAGE Publications.

Schwarz, N., \& Sudman, S. (1992). Context effects in social and psychological research. Chapel Hill: Springer.

Schwer, R. K., \& Daneshvary, R. (1995). Willingness to pay for public television and the advent of lookalike cable-television channels-A case study. Journal of Media Economics, 8(3), 95-109.

Seaman, B. A. (2006). Empirical studies of demand for performing arts. In D. Throsby \& V. Ginsburgh (Eds.), Handbook of the economics of art and culture (pp. 415-472). Amsterdam: North Holland.

Sellitz, C., Wrightsman, L. S., \& Cook, S. W. (1963). Research method in social relations. New York: Holt, Rinehart, and Winston.

Termansen, M., McClean, C. J., \& Jensen, F. S. (2013). Modelling and mapping spatial heterogeneity in forest recreation services. Ecological Economics, 92, 48-57.

Throsby, C. D. (1990). Perception of quality in demand for the theatre. Journal of Cultural Economics, $14(1), 65-82$.

Throsby, D. (2001). Economics and culture. Cambridge: Cambridge University Press.

Throsby, D., \& Ginsburgh, V. A. (Eds.). (2006). Handbook of the economics of art and culture. North Holland: Elsevier B.V.

Towse, R. (2010). A textbook of cultural economics. Cambridge: Cambridge University Press. 
Ulldemolins, J. R., \& Arostegui, A. R. (2013). The governance of national cultural organisations: Comparative study of performance contracts with the main cultural organisations in England, France and Catalonia (Spain). International Journal of Cultural Policy, 19(2), 249-269.

US Office of Management and Budget. (1992). Circular No. A-94 Revised (Transmittal Memo No. 64). Washington DC.

Van Den Hoogen, Q. L. (2014). New local cultural policy evaluation methods in the Netherlands: Status and perspectives. International Journal of Cultural Policy, 20(5), 613-636.

Vojtíšková, K., \& Lorencová, R. (2015). Public funding of culture in the Czech Republic since the fall of the Iron Curtain: Contemporary dilemmas. International Journal of Cultural Policy, 21(5), 529-553.

Wąsowska-Pawlik, A. (2013). Polityka Kulturalna Polski 1989-2012. In J. Hausner, A. Karwińska, \& J. Purchla (Eds.), Kultura i rozwój (pp. 107-126). Warszawa: Narodowe Centrum Kultury.

Willis, K. G., \& Snowball, J. D. (2009). Investigating how the attributes of live theatre productions influence consumption choices using conjoint analysis: The example of the National Arts Festival, South Africa. Journal of Cultural Economics, 33(3), 167-183.

Willis, K. G., Snowball, J. D., Wymer, C., \& Grisolía, J. (2012). A count data travel cost model of theatre demand using aggregate theatre booking data. Journal of Cultural Economics, 36(2), 91-112.

Wiśniewska, A., \& Czajkowski, M. (2017). Designing a socially efficient cultural policy: The case of municipal theaters in Warsaw. International Journal of Cultural Policy. https://doi. org/10.1080/10286632.2017.1308504.

Zawojska, E., \& Bartczak, A. (2019). Disentangling the effects of policy and payment consequentiality and risk attitudes on stated preferences. Journal of Environmental Economics and Management, 93, 63-84.

Zawojska, E., \& Czajkowski, M. (2017). Re-examining empirical evidence on stated preferences: Importance of incentive compatibility. Journal of Environmental Economics and Policy, 6(4), 374-403.

Zieba, M. (2011). An analysis of technical efficiency and efficiency factors for Austrian and Swiss nonprofit theatres. Swiss Journal of Economics and Statistics, 147, 233-274.

Publisher's Note Springer Nature remains neutral with regard to jurisdictional claims in published maps and institutional affiliations. 